\title{
Words of Tohkaku Wada: medical heritage in Japan
}

Masatoshi Matsumoto, Kazuo Inoue and Eiji Kajii Fujihashi Clinic, Gifu, and fichi Medical School, Tochigi, Fapan

\begin{abstract}
The origins of Japan's medical ideas, which are deeply rooted in its religion, culture and history, are not widely understood in medical societies of other countries. We have taken up the task of summarising this tradition here so that some insight can be gained into the unique issues that characterise the practice of medicine in fapan. We borrow from the sayings of Tohkaku Wada, a medical philosopher of late eighteenth-century fapan, for a look at fapanese medical tradition. Wada's medical thought was very much reflective of the Buddhism, Zen, and swordsmanship that informed eighteenth-century philosophy in Fapan. His central concepts were "chu" and "sei", that is, complete and selfless dedication to the patient and the practice of medicine. This paper explores Wada's thought, explaining it mainly from the standpoint of fapanese traditional culture.

(Fournal of Medical Ethics 2001;27:55-58)
\end{abstract}

Keywords: Tohkaku Wada; ethics; philosophy; Buddhism; Zen; Japan

\section{Introduction}

We cannot practise medicine effectively without knowing the culture and history that belong to the individuals we care for. With any system of medicine, philosophy is tied to "place," and the practice of medicine is continuously affected by both the culture and history of where it is located. In attempting to comprehend the system of medicine in any country, it is important to trace the footsteps of its early practitioners. In an oriental country that has been recently and rapidly Westernised, it is especially important to understand its rich cultural and philosophical heritage. We are exposed to many books on medical philosophy and bioethics, but most of them are written in Western countries. Though modern Western medical ideas have considerable universal validity, some aspects are unnatural in oriental countries where traditional cultures are deeply rooted. ${ }^{1}$ The separate Asian countries must have their own medical philosophies, all of which are closely tied to local culture, religion, and history. On the other hand if we want medical philosophy or ethics for the whole world, we should not ignore these oriental medical ideas.

Here we explore the medical philosophy of Japan in words written more than two hundred years ago by an influential Japanese doctor who is considered a key representative of the medical society of eighteenth-century Japan. ${ }^{2}$ We take this man as an example because we consider his philosophy is a good example of the medical thinking in Japan before the influx of Western culture and science.

\section{Tohkaku Wada}

Tohkaku Wada is one of the distinguished practitioners of indigenous Japanese medicine. He was born in 1743, the son of a doctor in Osaka, Japan. His era, the Edo period (1600-1868), witnessed the stabilisation of the system of local rule by military lords (daimy) under strong shogunal authority in Tokyo $(E d o)$. A ruling class of samurai monopolised all functions of government. Under a policy of "national seclusion", the Tokugawa shognate restricted foreign contact except for trade with Holland and China in Nagasaki. It was not until the mid-nineteenth century that Japan opened its doors to foreign countries, a move which led to rapid modernisation. Thus the era in which Wada lived was a time when an inherently Japanese culture flourished, and indeed, reached its peak. ${ }^{3}$ During the Edo period, most Japanese doctors learned Kampo medicine - the Japanese system of herbal medicine rooted in traditional Chinese medicine. Only a small number of practitioners knew Western medicine-mainly through Dutch medical books. ${ }^{4}$ Thus, Wada's medicine was based on Kampo medicine. He was taught, starting in 1769 , by Tohdo Yoshimasu, the most famous Kampo doctor in Japan at that time. ${ }^{5}$ Most Kampo doctors in Wada's period attached great importance to classical Chinese medical texts and practised "textbook" medicine faithfully. Together these doctors were called the "kohha," the classical school. Although Wada recognised the importance of classical Chinese texts, he simplified the complicated theory of traditional Chinese medicine, saying: "Those who use simplified remedies can use sophisticated art". He established his own diagnostic and therapeutic theories, separate from the old, rigid medical theories, believing that, "with too much legal restriction, we encounter a dead law; in freedom from such restriction, we find an active law". 5 Owing to his and his colleagues' efforts, Kampo medicine succeeded in breaking away from traditional Chinese medicine and developed in Japan as a simplified and practical herbal medicine system in its own right. With rapid Westernisation, however, during the Meiji era (1868-1911), utilisa- 
tion of Kampo declined among Japanese doctors, and the practice of Kampo was driven underground. However, because of its positive contribution to individual health and wellbeing, Kampo is being rediscovered, and is being incorporated into clinical practice today. Seventy-eight per cent of Japanese doctors now prescribe Kampo drugs regularly, and sales were 93.4 billion yen (US $\$ 0.9$ billion) in $1998 . .^{6}$

Wada, widely known throughout Japan for his clinical ability, became the personal physician of an aristocrat, Nijo, in Kyoto. He then had the opportunity, it seems, to cure the infertility of the empress, using Bushi (aconite root). This even impressed the emperor who, in 1799, promoted Wada to "Hogan," the highest position in Japanese medical society. Even now, Wada's name is recognised widely among students of Kampo as the model clinician of the Edo period. ${ }^{2}$ Though Wada taught many medical students, he did not like to record his teaching or thought, saying: "I can't express the essence of my mind by words or letters". ${ }^{5}$ Thus, most of the books on his practice of medicine were written by his pupils after he died. Most of these books present his theories of clinical diagnosis and treatment; only Syszatsuzwa describes his medical philosophy. In Japan, books on medical philosophy or medical ethics are known as "Ikun." Among the existing Ikuns, Syosozatsuwa is the most famous; Wada's thought is considered to be representative of Edo-period Japanese medical philosophy. $^{2}$

We quote herein from the Syosozatsuwa. ${ }^{5}$ We have selected sections that well represent Wada's philosophy, and we explain them in terms of Zen, Buddhism and swordsmanship (samurai spirit) which influenced the Japanese culture of the time.

\section{Wada's medical philosophy}

"The way of medicine is solely through chu and sei." 5

Wada repeats this conviction throughout the Syosozatsuwa. He insists that the doctor should be absolutely and truly dedicated to the patient and his clinical art. "Chu" and "sei" are philosophical terms that originate in Japanese swordsmanship or "samurai spirit". Originally, chu meant absolute obedience and loyalty to the samurai's monarch, and sei (another word for this is "makoto") means total accord between one's words and one's deeds or between one's words and one's mind. ${ }^{7}$ Swordsmanship is the philosophy that tells the samurai how to fight on the battlefield, but it also teaches him how to live and how to die in feudal society The basic concepts of the samurai spirit are: jinn (sympathy, virtue); gi (justice, morality); rei (manners, politeness); chi (wisdom); chu; sei and kokki (self control). Among these, $c h u$ and $s e$ i, which are found in the quote above, are also found in Confucianism - the old Chinese philosophy that greatly influenced the samurai spirit. Swordsmanship had a great influence not only on the samurai class but also on common people of the time ${ }^{8}$ thus, Wada was exposed to what was once the philosophy of the elite.

"When you see a neurotic patient, you should heal him with your words. However, you should never use superfluous words nor rely on logic when trying to help neurotic people. Words and logic are superficial. You should be in the mind of $c h u$ and sei and speak the words that come from within. The attitude of pure $c h u$ has a power that can penetrate a rock."

This is an example of Wada's emphasis on spiritual matters such as chu and sei rather than on matters of reason; his approach to the patient was a spiritual one. Such a relatively spiritual attitude, which often transcends logic, is frequently seen in oriental countries, especially in Japan, and is often contrasted with Western rationalism by scholars of comparative philosophy.

"If you hope to perfect your clinical art, you must be absorbed in the art. If you are distracted, that is, if your mind meanders in various directions, you will never arrive at a deep and sophisticated understanding of your art. If you can control the distraction of your mind and if your mind runs only in one direction, you will find clues to your art in your daily activities,-in walking in the mountains or in handling a tray. Being absorbed in your art day and night, you will achieve satori - enlightenment-you will feel as though you are living in paradise. Absorption is the way to the high art of medicine."

Wada repeatedly emphasises the importance of the individual's absorption in his art, as exemplified by the master spearman. "Sator"" is the instinctive grasp of the essence of a thing. ${ }^{10}$ It is a fundamental element in Buddhism. Buddha teaches that the purpose of life is to achieve satori; that is, to reach "nehan" (nirvana in Sanskrit; the state beyond life and death, a kind of paradise) and that the feeling of satori cannot be told well nor written. ${ }^{11}$ Wada, too, said: "The way to satori cannot be told well nor be written by letters. And the satori of medicine is very difficult to express. So you must achieve by your own experience, not by other people's words."

Buddhism teaches that to achieve satori, one has to eliminate the flames of craving and make one's self void. This pure and completely absorbed desire for truth is called "zanmai" (samdhi in Sanskrit). Mahyna Buddhism, to which Japanese Buddhism belongs, proposes that every aspect of daily life is connected to nehan; therefore, even the common person, the non-priest, can achieve satori by achieving zanmai in daily activities - a doctor can apply zanmai in his medical practice, for example. ${ }^{12}$ The concepts of satori and zanmai are most strikingly presented in Zen. Zen is a school of Mahyna Buddhism born in late fifth-century India. Zen departed from the highly complicated theory of Buddhism written in many sutras. In Zen, satori is achieved by meditation - sitting and meditating in the way of Buddha. Zen insists that it is not possible to achieve satori from words or thought, especially from rationalism, but it is possible by 
achieving zanmai in real experience, mainly through sitting and meditating but also in every aspect of daily activity. ${ }^{10}$ We can find this influence of Buddhism, especially of Zen, in Wada's concept of absorption and satori. He insisted that the purpose of practising medicine is to achieve satori, and he emphasised the importance of being absorbed in the art of medicine, saying that satori in medicine leads doctors to a kind of "paradise", that is, nehan. In Japan, the concept of satori and zanmai is recognised not only in the Way of medicine but also in the Ways of other disciplines such as Kendo, Judo, Sado (tea ceremony). ${ }^{13}$

"Those who hope to make the seriously diseased patient live by their own hands love themselves. Those who hope to make the patient die in their own hands love the patient. Those who love themselves cannot devote themselves to the patient, but those who love the patient devote themselves purely to him."

Wada's words here express the attitude a doctor should have when handling a serious case. The meaning here is this: a doctor who sees his patient's need for a good death truly loves his patient, and such doctors are better than doctors who care only that the patient should live. The truly loving doctor might consider the management of a patient's death to be more difficult than that of the patient's life: a strong trust and true love between the doctor and his patient are necessary for the patient to achieve a good death. Today, this concept of a good death has become important in the face of life-support techniques and when questions to do with euthanasia and "death with dignity" arise.

From the Western viewpoint, "Those who hope to make the patient die in their own hands love the patient" may seem contradictory and vague. However, in oriental countries there has been a tendency to express truth in seemingly contradictory and vague terms like this. This is particularly true in Zen. As expressed by Zen scholar D T Suzuki "Truth says passive is active and negative is positive. This is called an identity of absolute contradiction, and we can find the soul of Zen and Buddhism in it". ${ }^{14}$ C G Jung, too, said: "The abstruse obscurity of the Zen concept conveys a great deal more, while saying less". ${ }^{15}$

Another example of the influence of Buddhism is clear in Wada's words:

"When a medical master sees a patient, he does not recognise the patient as the patient. He recognises the patient as himself. There is no distinction between 'I' and 'you' in his mind. In this way, the master knows very well about the patient and the patient's disease."

Wada seems to have considered a doctor's ability to step beyond the bounds of his own identity and a doctor's sense of oneness with his patient as an ideal. In contemporary Western thought, subject and object are clearly distinguished. That is, the ideal doctor is the doctor who does not cross the boundary of his own well-established identity and who analyses his patient's condition rationally. ${ }^{16}$ From the Western point of view, Wada's thought that the doctor must transcend his own identity and unify himself with the patient may be difficult to understand. However, the importance of attaining this state of complete selflessness, the so-called undivided state, ${ }^{14}$ which is very near the state of nehan, is repeatedly advocated by Buddha in his primitive sutras, and is a fundamental concept of Buddhism. Buddhism has affected many aspects of thought in Japan, ${ }^{17}$ and from Wada's words we see that medical philosophy during his time was not an exception.

From his traditional Japanese way of thinking, Wada responded to the question of how doctors should view terminally ill and dying patients:

"If you think the patient is severely ill, you should tell him honestly the limitations of your medicine and that you cannot predict whether or not he will live into the near future. If he entrusts you with his life, you should treat him only in the mind of chu and $s e i$. You should devote everything to him, considering nothing but his recovery. Be of such a mind that if his condition does not change according to your hope, his imminent death is yours to ensure."

This expression seems to be a contradiction of the Hippocratic Oath: "I will give no deadly medicine to anyone". Western humanitarianism and rationalism may not understand such an expression; the doctor who strives to wash himself away and who unifies himself with his patient cannot bear to see the patient experience an unsatisfactory death. It was not unnatural for people throughout Japanese history, especially people in the samurai class, to "give" death rather than allow themselves or another to succumb to a dishonourable death. Japanese swordsmanship fostered a distaste for the dishonourable or undesirable death; hara-kiri suicide and mercy killing were more honourable. Highly spiritual death aesthetics like this are characteristic of Japanese swordsmanship. ${ }^{8}$ To give someone the opportunity of this honourable death is called "bushi-no-nasake: pity of the samurai", and the people of the time tended to see the spiritual aspect behind it rather than the brutal nature of the deed itself. Thus Wada's philosophy on death and dying and the physician's role was not unorthodox; rather, it was accepted as a part of the ideal doctorpatient relationship.

\section{Conclusion}

As we explained, Wada's is a medicine of chu and $s e i$, established against a background of traditional Japanese social thought. In terms of the physician's effort toward his patient and his art, his philosophy matches that of Western medicine. However, his philosophy transcends a mere "doing your best" to reach "complete dedication to the patient and the art". In addition, he strove for ultimate truth through this dedication. $\mathrm{He}$ never considered medicine as an aggregate of knowledge and skill, he considered it "mich" ("tao" in Chinese; literally, "the Path" "the Way": a fundamental principle 
underlying the universe) and he attached the greater importance to its spiritual aspect. This highly spiritual medical philosophy, which strives to transcend the confines of logic seems to be quite different from the medical philosophy of the West, which has developed under the influence of rationalism and Christianity. Generations of medical students have been told: "Don't get involved: keep your distance from the patient". This is supposed to be the correct attitude of the physician; that of a detached observer. However, Wada's idea of complete selflessness, of giving "undivided" attention to the patient, raises the question whether such an attitude is correct in any time, for any person, and in any culture.

Even in developed, Western countries, an increasing number of people are now using traditional oriental medicine such as acupuncture and herbs. ${ }^{18}$ However, traditional medical philosophy and the ethics of oriental countries seem to be poorly understood by Western people.

We have a lesson, "I wa jinjutsu nari" (medicine is the art of sympathising), which was written in a book more than one thousand years ago and even now this phrase is often used in Japan, when discussing the ethics of doctors, or medical ethics. It is clear therefore, that traditional thought is still alive in the minds of Japanese people. If one wishes to have a deep understanding of Japanese medicine, one should study old Japanese literature such as Syosozatsuwa ${ }^{5}$ in order to come to know the roots of Japanese medical ethics. Because Wada's thought contains little of the concept of autonomy and patient self determination, which are central concepts of modern bioethics, ${ }^{1}$ we cannot apply his teaching as it stands to the contemporary practice of medicine. However, we should evaluate and preserve these Japanese or oriental ways of medical thinking, which we believe will be necessary for the construction of global medical ethics or philosophy, for future generations.

Masatoshi Matsumoto, MD, is a Family Physician, Fujihashi Clinic, Gifu, Fapan and Senior Resident, Department of Community and Family Medicine, Fichi
Medical School, Tochigi, fapan. Kazuo Inoue, MD, PhD, is a Family Physician, Towa Clinic, Department of Community and Family Medicine, Fichi Medical School and Eiji Kajii, MD, PhD, is Professor in the Department of Community and Family Medicine, Fichi Medical School. Correspondence to: Dr M Matsumoto, Department of Community and Family Medicine, 3311-1 Yakushiji, Minami-Kawachi, Tochigi 3290498, fapan. Telephone: 0285-58-7394; fax: 0285-440628.Email:matmolo@jb3.so-net.ne.jp

\section{References}

1 Jecker NS, Jonsen AR, Pearlman RA. Bioethics: an introduction to the history, methods, and practice. Sudbury: Jones and Bartlett Publishers, 1997: 383-401.

2 Matsuda K. The heart of medicine. Fapanese fournal of Oriental Medicine 1999;50:1-10.

3 Encyclopaedia of fapan. Fapanese History: 11 experts reflect on the past. Tokyo: Kodansya-International, 1996: 96-113.

4 Araki M. The character and origin of fapanese Kampo. Tokyo: Oraki M. The character and origi

Ochanomizu-syobo, 1988.20-89. Wada 1. Tokyo: Meicho-syuppan, 1979: 5-29.

Wada 1. Tokyo: Meicho-syuppan, 1979: 5-29. 6 Matsumoto M, Inoue K, Kajii E. Traditional and Western medicine in concert in Japan: a model for others? Complementary Therapy and Medicine 1999;7:254-5.

7 Akatsuka T, Abe Y. Chinese characters dictionary. Tokyo: Ohbunsya, 1977: 412.

8 Nitobe I. Swordmanship. Tokyo: Iwanami-bunko, 1938: 25-57. 9 Nakamura H. The direction of comparative philosophy. Tokyo: Tokyo-syuppan, 1993: 11-41.

10 Suzuki DT. An introduction to Zen Buddhism. New York: Grove Press, 1964: 88-99.

11 Tamaki K, Kimura K. The world of Buddha. Tokyo: NHK books, 1992: 116-35.

12 Uryu N. An introduction to Buddhism. Osaka: Sohgensya, 1994: $71-6$.

13 Suzuki DT. Zen and fapanese culture. Princeton: Princeton University Press, 1959: 1-37.

14 Suzuki DT. The oriental way of thinking. Tokyo: Iwanamibunko, 1997: 69-72.

5 Jung CG. Psychology of oriental meditation. Osaka: Sohgensya, 1983: $175-218$.

16 Tumulty PA. The effective clinician. Tokyo: Igaku-Syoin, 1981: $1-17$.

17 Nakamura H. Selected essays of Hajime Nakamura. Osaka: Toho-syuppan, 1988: 146-237.

18 Eisenberg DM, Kessler RC, Foster C, Norlock FE, Calkins DR, Delbanco TL. Unconventional medicine in the United States: prevalence, costs and patterns of use. New England fournal of Medicine 1994;328:246-52. 